\title{
Pancreatic islet allograft prevents basement membrane thickening in the diabetic rat retina
}

\author{
A.A. F.Sima ${ }^{1}$, S. Chakrabarti ${ }^{1}$, W.J.Tze ${ }^{1}$ and J. Tai ${ }^{2}$ \\ ' Neuropathology Research Laboratories, Department of Pathology, University of Manitoba, Winnipeg, Manitoba, and \\ ${ }^{2}$ Department of Endocrinology, University of British Columbia, Vancouver, British Columbia, Canada
}

\begin{abstract}
Summary. Progressive basement membrane thickening is a characteristic structural abnormality in diabetic tissues including the retina. We examined the effect of pancreatic islet allotransplantation on basement membrane thickening and irregularities in retinal capillaries of the streptozotocin-diabetic rat. Diabetic animals received intraportal or intracerebral pancreatic islet allografts. Animals with functioning allografts demonstrated euglycaemia and a normal body weight gain during the 400-day post-transplantation period. The
\end{abstract}

characteristic thickening of capillary basement membranes was completely prevented in animals with successful transplantation. The present findings suggest that islet allotransplantation may be a rational therapeutic approach in the treatment of diabetes mellitus and the prevention of ensuing secondary complications.

Key words: Islet cell transplantation, streptozotocin-diabetic rats, basement membrane, retina.
Pancreatic islet cell transplantation is a rational approach to the treatment of diabetes mellitus and its complications, since it has been suggested that hyperglycaemia conditions the development of secondary complications in diabetes such as retinopathy [1]. Hence, if a physiological glucose homeostasis can be achieved by means of pancreatic islet transplantation the secondary complications may be prevented or halted [2].

Thickening of capillary basement membranes is a prominent abnormality in the target organs prone to diabetic complications, including the retina. Although improvement of the blood retinal barrier permeability [3], normalisation of the pericyte-endothelial cell ratio [4], and prevention of retinal neovascularisation [5, 6] have been claimed following pancreas or islet cell transplantation, no report is available with regard to its effect on retinal capillary basement membrane. However, the occurrence of neovascularisation in the diabetic rat retina has been disputed [7]. Previous observations have been made either following isografts $[3,4]$ or allograft transplantation across a weak histocompatibility barrier [5].

In this communication, we report on retinal basement membrane thickening in the streptozotocin (STZ)-diabetic rat following islet cell transplantation across a major histocompatibility barrier.

\section{Material and methods}

\begin{abstract}
Animals
Twenty-nine inbred male Lewis rats of the $\mathrm{AC} 1(\mathrm{AgB} 4 / 4)$ strain were used. Twenty-four rats were made diabetic at the age of 4 months by intravenous injection of STZ $(50 \mathrm{mg} / \mathrm{kg}$ body weight). Diabetes was defined by fasting blood glucose levels greater than $22 \mathrm{mmol} / \mathrm{l}$ on three successive occasions. Pancreatic islet cell transplantation was carried out in 19 rats $12.8 \pm 3.4$ days (mean $\pm S D$ ) following induction of diabetes.
\end{abstract}

\section{Transplantation procedure}

Male inbred Lewis rats (Le; $\mathrm{Ag} \mathrm{Bl} / \mathrm{l}$ ) with a body weight of $350-500 \mathrm{~g}$ were used as donors of pancreatic tissue.

The donor animals were anaesthetised with sodium pentobarbital $(50 \mathrm{mg} / \mathrm{kg}$ of body weight) (Abbott Laboratories, Montreal, Quebec, Canada). A midline laparotomy was made and the pancreas was dissected. Pancreatic tissue was digested with collagenase and islets were hand picked under a dissecting microscope. Contaminating acinal tissue and blood vessels were removed using the single layer $\mathrm{Hy}-$ paque-Ficoll separation technique. Clean islets collected at the interface were either cultured at $26^{\circ} \mathrm{C}$ in $5 \% \mathrm{CO}_{2}$ for 1 week prior to transplantation or immediately dissociated into single pancreatic endocrine cell suspensions with a combination of EDTA and trypsin treatment. The preparation of pancreatic pseudo-islets was carried out by culturing pancreatic endocrine cells at $37^{\circ} \mathrm{C}$ in $5 \% \mathrm{CO}_{2}$ for 5 days to allow cellular aggregation to occur [8].

For intraportal allotransplantation a total of 1500 pancreatic whole islets or pancreatic pseudo islets suspended in $200 \mu \mathrm{l}$ culture medium were injected slowly into the portal vein of 11 STZ-induced diabetic AC1 recipients. For intracerebral transplantation, 1500 pan- 
Table 1. Effect of pancreatic islet allograft on capillary basement membrane thickness (BMT) in the various experimental rat groups, and comparisons of BMT in the superficial and deep capillary beds within groups

\begin{tabular}{|c|c|c|c|c|}
\hline Groups of rats & $(n)$ & $\begin{array}{l}\text { Superficial capillary bed } \\
\text { BMT nm }(\text { mean } \pm \text { SD) }\end{array}$ & $\begin{array}{l}\text { Deep capillary bed } \\
\text { BMT nm (mean } \pm \text { SD) }\end{array}$ & $\begin{array}{l}\text { Significance of difference } \\
\text { between superficial and } \\
\text { deep capillary BMT }\end{array}$ \\
\hline 1 Intraportal rejected & (5) & Г $189.8 \pm 13.5$ & $\ulcorner-134.2 \pm 7.2$ & $p<0.001$ \\
\hline 2 Intracerebral rejected & (4) & $-194.5 \pm 14.7$ & $-135.3 \pm 8.3$ & $p<0.001$ \\
\hline 3 Intraportal accepted & (6) & $\left.\right|_{p<0.001 \quad p<0.001} ^{159.7 \pm 12.97}$ & $\left.\right|_{D<0.001} 108.7 \pm 10.37$ & $p<0.001$ \\
\hline 4 Intracerebral accepted & (4) & $\left|\begin{array}{l}157.3 \pm 24.1 \\
p<0.001\end{array}\right|$ & $\left|\begin{array}{l}110.9 \pm 14.4 \\
p<0.002\end{array}\right|$ & $p<0.02$ \\
\hline 5 Diabetic non-transplanted & (5) & $\begin{array}{l}210.7 \pm 6.6 \\
p<0.001\end{array}$ & $\begin{array}{l}149.1 \pm 3.8 \\
p<0.001\end{array}$ & $p<0.001$ \\
\hline 6 Controls & (5) & $L 146.2 \pm 6.7$ & $L \quad 97.4 \pm 7.5$ & $p<0.001$ \\
\hline
\end{tabular}

All $\mathrm{p}$ values given in the table were obtained using Student's t-test. Intergroup analysis of BMT in the superficial capillary bed using one way analysis of variance yielded a variance ratio of $16.19(p<0.001)$ and that of the deep capillary bed a variance ratio of $22.97(p<0.001)$. Note that the basement membrane thickness in the groups with accepted grafts ( 3 and 4 ) are not significantly different from controls (VI)

creatic whole islets or pancreatic endocrine cells $\left(2-3 \times 10^{6}\right.$ viable cells) suspended in a $50 \mu \mathrm{l}$ culture medium were implanted stereotaxically into the right hemisphere of the brain of eight diabetic recipients. Blood glucose, body weight, 24 -h urine volume and urine sugar were monitored daily prior to and for two weeks after allotransplantation and at regular intervals thereafter. Acceptance of allografts was defined by the presence of normoglycaemia and normal weight gain in the diabetic recipients as previously described in detail [9]. The islet allografts of five intraportally and four intracerebrally transplanted animals were challenged with skin grafts from the same donor strain 7 to 10 days following transplantation. Rejection was considered to have occurred when the blood glucose level exceeded $11 \mathrm{mmol} / \mathrm{l}$ on two consecutive days following skin grafting.

\section{Clinical monitoring}

All animals were housed individually in air-filtered metabolic cages and given rat-chow (Wayne Lab Blox F-6, Wayne Feed Division, Chicago, Ill, USA), and water ad libitum. Diabetic animals were monitored bi-weekly with respect to blood-sugar and body-weight. All animals were killed at 18 months of age and the following groups of animals were investigated; 1) animals with intraportal transplant (rejected) $(n=5)$; 2) intracerebral transplant (rejected) $n=4 ; 3$ ) intraportal transplant (accepted) $(n=6) ; 4)$ intracerebral transplant (accepted) $(n=4)$; 5 ) diabetic non-transplanted $(n=5)$, and 6$)$ non-diabetic control rats $(n=5)$. All animals were anaesthetised by intraperitoneal injection of sodium pentobarbital $(50 \mathrm{mg} / \mathrm{kg}$ body-weight) (Abbott Laboratories, Montreal, Quebec, Canada), and killed by whole body perfusion through the left ventricle with a $0.1 \mathrm{~mol} / 1 \mathrm{ca}-$ codylate buffered ( $\mathrm{pH} 7.4$ ) $2.5 \%$ glutaraldehyde solution.

\section{Morphological techniques}

Both eyes were enucleated and post-fixed in the same glutaraldehyde fixative for 4 to $6 \mathrm{~h}$ at $4^{\circ} \mathrm{C}$. Qualitative and quantitative light and electron microscopic studies were performed using the right eye of each animal. The examiner was not aware of the identity of the tissues.

\section{Qualitative studies}

After fixation, radially oriented retinal segments $\left(1 \mathrm{~mm}^{2}\right)$ were taken from the superior temporal quadrant near the optic nerve head. They were washed overnight in $0.1 \mathrm{~mol} / 1$ cacodylate buffer $(\mathrm{pH} 7.4)$. The tissues were post-fixed in cacodylate buffered $1 \%$ osmium-tetroxide
(pH 7.4) for $2 \mathrm{~h}$, dehydrated in graded alcohol and embedded in Epon. Semithin, toluidine blue stained sections $(0.5 \mu \mathrm{m})$ were used for light microscopic orientation. Ultrathin sections were stained with aqueous uranyl acetate and lead citrate, and examined electronmicroscopically.

\section{Quantitative structural studies}

Morphometric studies were performed with the aid of a HewlettPackard 9874A digitizer connected with a Hewlett-Packard 9825A desktop computer (Hewlett-Packard Co, Fort Collins, Col, USA).

Basement membrane thickness (BMT) was measured according to a modification [10] of the technique described originally by Robison et al. [11]. Twenty randomly selected and transversly sectioned capillaries were photographed from each animal, 10 from the deep capillary bed, located in the outer plexiform layer and inner nuclear layer, and 10 from the superficial capillary bed, located in the nerve fibre layer and ganglion cell layer. Measurements were made from electronmicrographs enlarged to a final magnification of 16,000 times. Basement membrane area (BMA) and basement membrane length (BML) were determined as follows:

$\mathrm{BMA}=\mathrm{T}-(\mathrm{L}+\mathrm{P}+\mathrm{E})$; where $\mathrm{T}=$ total capillary area, $\mathrm{L}=$ lumen al area, $\mathrm{P}=$ pericyte profile area and $\mathrm{E}=$ endothelial cell profile area.

$\mathrm{BML}=\frac{\text { length of lines delimiting the } \mathrm{BM}}{2}$

The relative thickness of the basement membrane was expressed as area per unit length BMT $(\mathrm{nm})=\left[\mathrm{BMA}\left(\mu \mathrm{m}^{2}\right) / \mathrm{BML}(\mu \mathrm{m})\right] \times 1000$. To ascertain that the capillaries were cross-sectioned, only those with sharp circumferential delineations of the basement membrane borders were used for the measurements. The same electronmicrographs were used to examine qualitative basement membrane abnormalities.

\section{Statistical analysis}

All values are expressed as mean $\pm \mathrm{SD}$. One way analysis of variance and Student's t-test were used to determine significance of difference. A p value less than 0.05 was accepted as significant.

\section{Results}

\section{Clinical observations}

Successful islet allotransplantation resulted in normalisation of the blood sugar levels in previously diabetic 
animals (Fig.1), whereas animals in whom allograft rejection was induced showed a return to significant hyperglycaemia (Fig. 1). The characteristic decrease in body weight gain in diabetic rats was ameliorated by

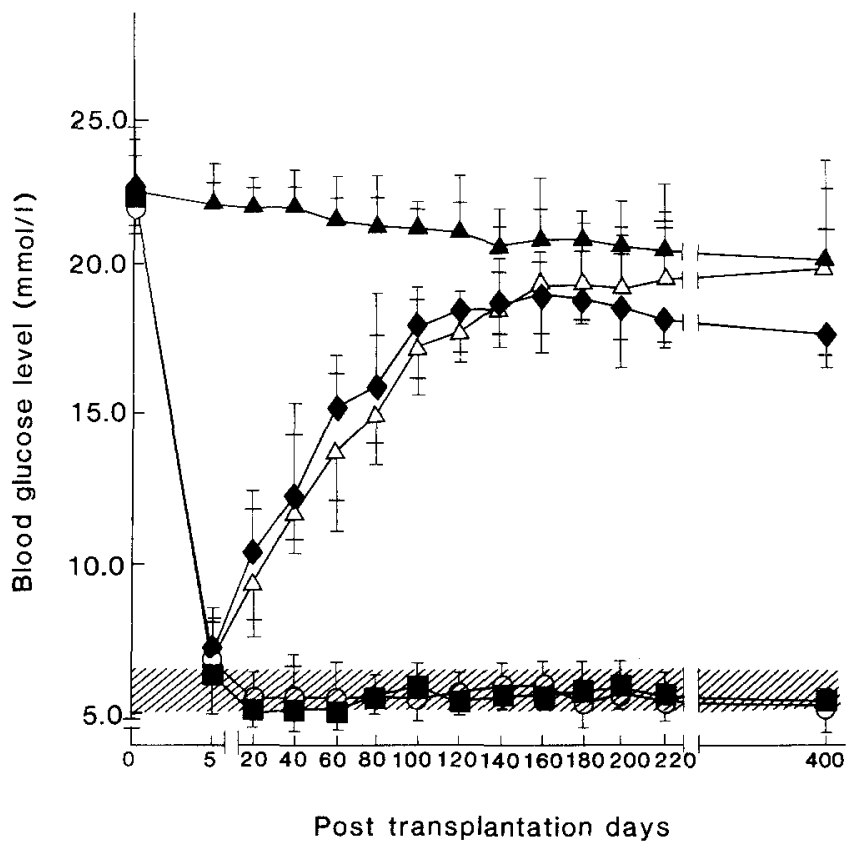

Fig. 1. Blood glucose levels, mmol/1 (mean \pm SD) in the various groups during the 400 -day post transplantation period. Note the recurrence of hyperglycaemia in groups with graft rejection. Intraportal transplant, rejected $(n=5)(\Delta-\Delta)$; Intracerebral transplant, rejected $(n=4)(-)$; Intraportal transplant, accepted $(n=6)$ $(\mathrm{O}-\mathrm{O})$; Intracerebral transplant, accepted $(n=4)(-)$; Diabetic non-transplanted $(n=5)(\mathbf{\Delta} \mathbf{\Lambda})$; Shaded area, non-diabetic controls $(n=5)$. Day $0=$ day of transplantation. successful islet transplantation, whereas animals with rejected allografts showed a body weight similar to that of non-transplanted diabetic rats (Fig.2).

\section{Qualitative basement membrane changes}

Basement membrane irregularities were seen in all animals except for non-diabetic control rats. These changes, although not quantified, appeared to be more common in rats with rejected grafts and in diabetic non-transplanted animals. The irregularities consisted of localised nodular thickenings and the deposition of

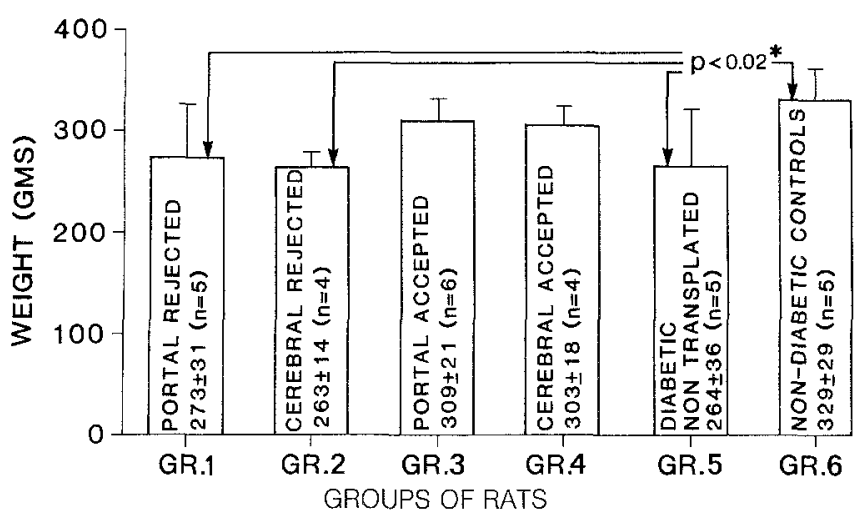

Fig. 2. Body weights (mean \pm S. D.) of the different groups at the time of killing showing significantly lower body weights in animals with rejected grafts (Groups 1 and 2) and in diabetic non-transplanted animals (Group 5).

* p-value obtained following Student's t-test. One way analysis of variance yielded a F-value of $5.31(p<0.005)$.

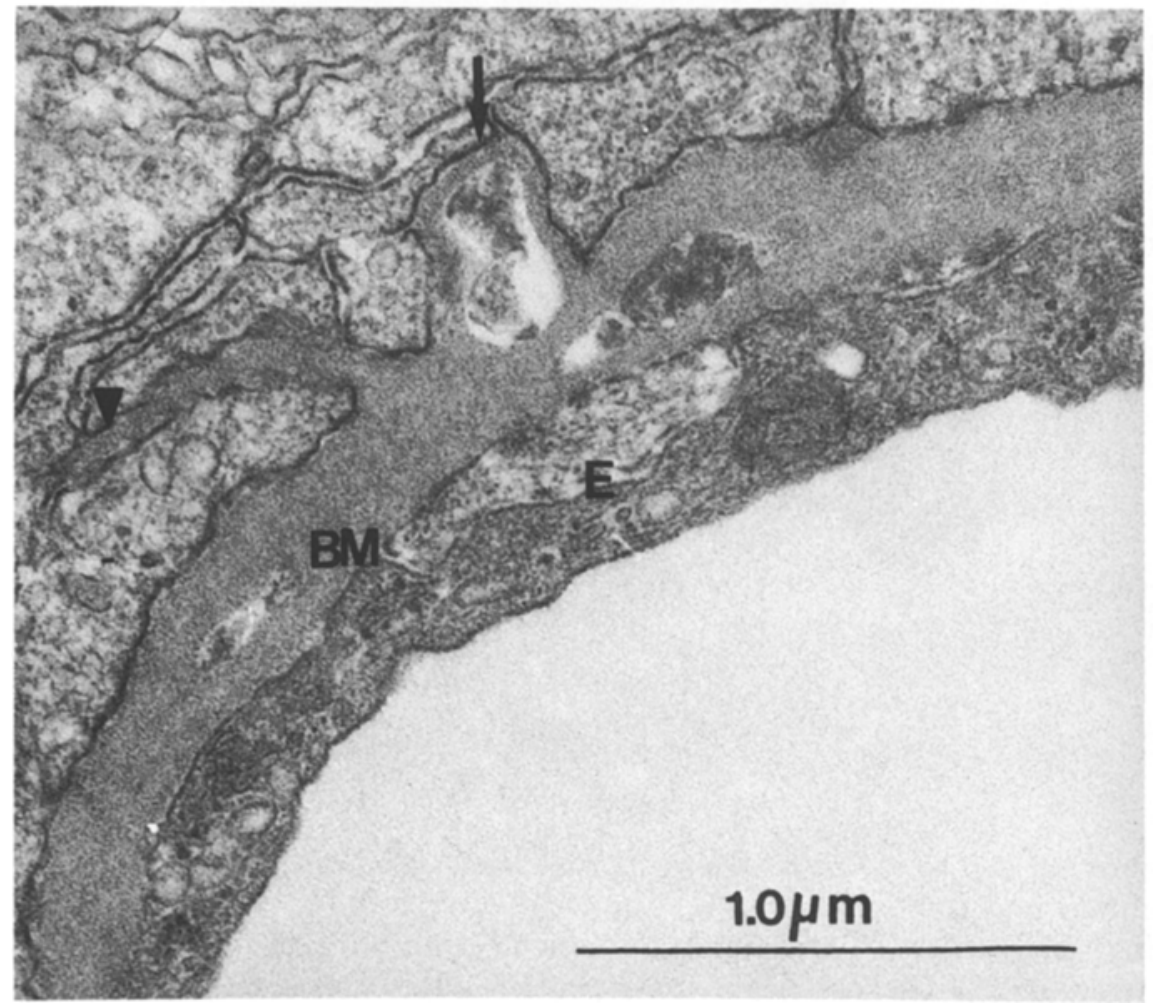

Fig.3. Electronmicrograph of a retinal capillary in a diabetic non-transplanted rat showing basement membrane irregularities, nodular thickening (arrow) and projection of basement membrane material between the surrounding glial processes (arrowhead). $\mathrm{BM}=$ basement membrane, $\mathrm{E}=$ endothelial cell. Magnification $51,000 \times$ 

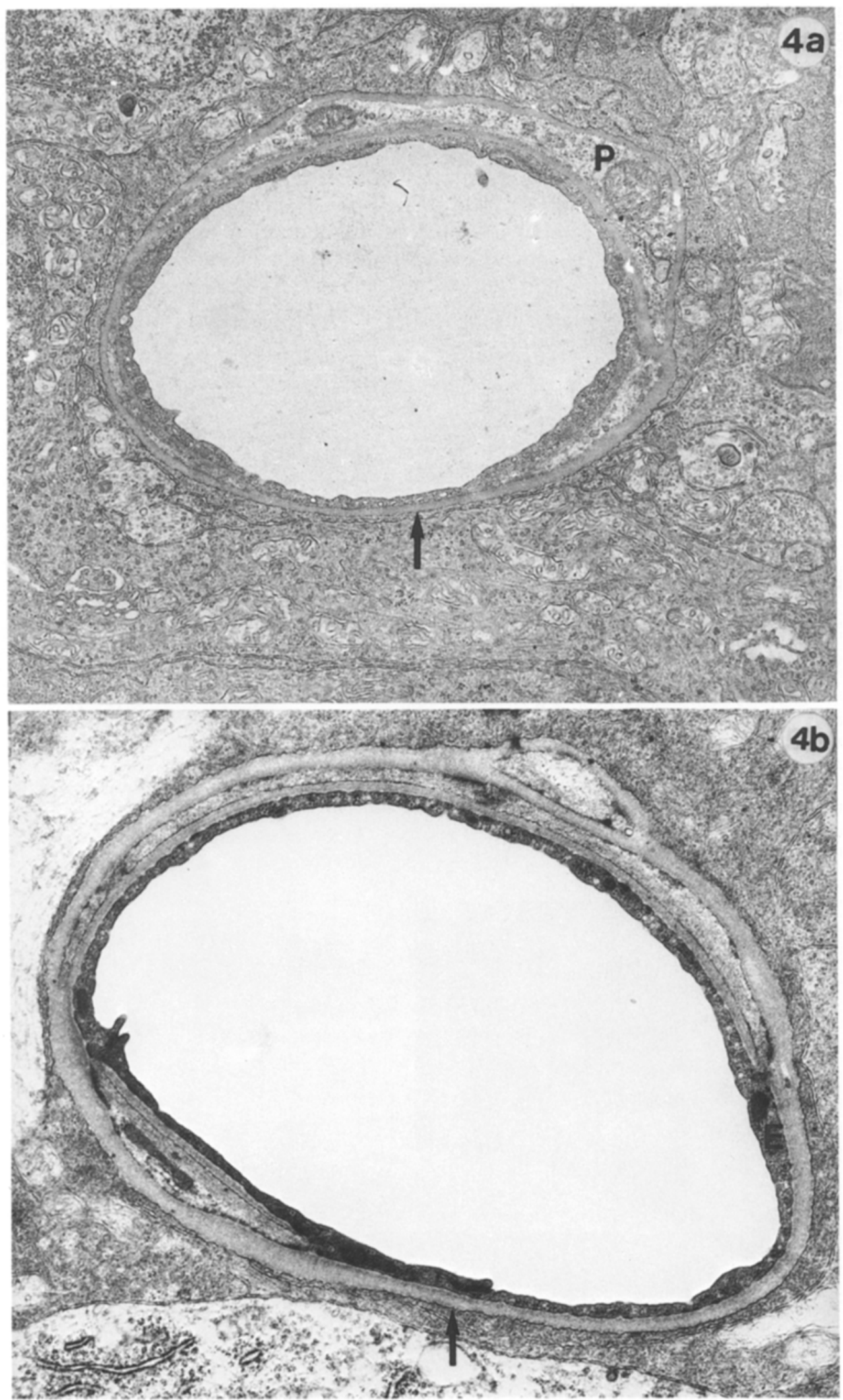

Fig.4. Cross-sections of retinal capillaries from the deep capillary bed showing the effect of pancreatic islet cell allotransplantation on basement membrane thickness (BMT). (a) non-diabetic control, BMT $=$ $100.1 \mathrm{~nm}$; (b) diabetic non-transplanted, BMT $=177.5 \mathrm{~nm}$; (c) graft rejected animal, $\mathrm{BMT}=148.5 \mathrm{~nm}$; (d) graft accepted animal, BMT = $113.5 \mathrm{~nm}$; Arrows are pointing towards the basement membrane. $\mathrm{P}=$ pericyte, $\mathrm{E}=$ endothelial cell The magnification is same for a-d: $13,000 \times$ fibrillar material in the basement membrane, as well as finger-like projections of basement membrane material between the processes of surrounding glial cells (Fig. 3).

\section{Basement membrane thickness (BMT)}

All animals examined showed thicker basement membranes in the superficial capillaries than in the capilla- 


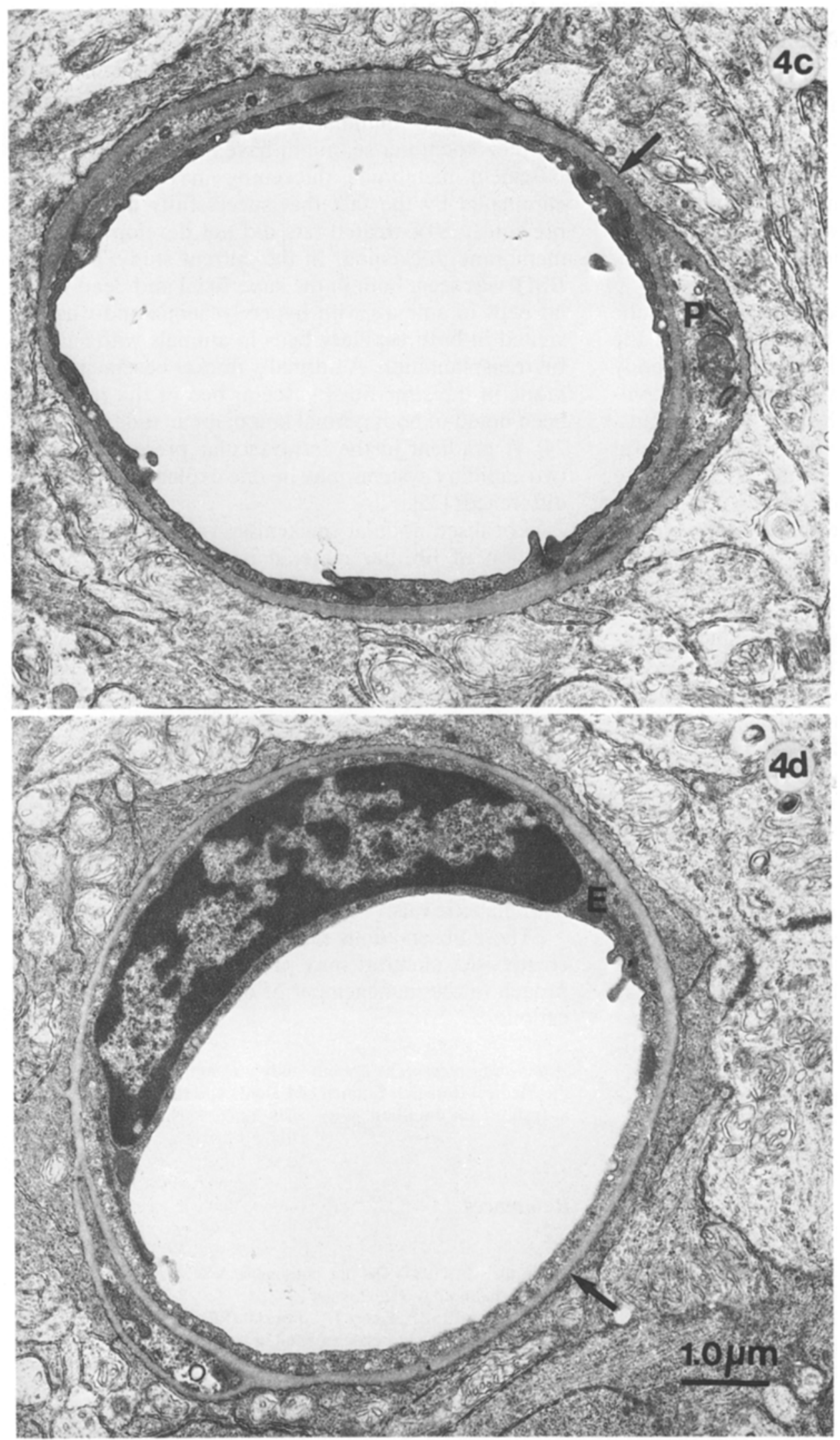

ries of the deep bed (Table 1). Diabetic non-transplanted animals showed a significant increase in BMT in both capillary beds compared with normal control rats $(p<0.001)$. This was also the case in transplanted animals with rejected grafts. In contrast, both intraportal and intracerebral successful allotransplantation result- 
ed in a complete prevention of capillary basement membrane thickening in both vascular beds of the retina (Table 1, Fig. 4).

\section{Discussion}

The present study has demonstrated that pancreatic islet cell allotransplantation successfully prevents basement membrane thickening in the retina of previously STZ-diabetic rats.

Two simple parameters reflecting good metabolic control in diabetes mellitus are body weight and the degree of hyperglycaemia. Both the characteristic body weight loss and hyperglycaemia were found to be completely normalised in animals with successful allotransplantation, while, as would be expected, unsuccessful transplantation did not show the same effects. These findings are in keeping with those of other investigators who have described improvement in body weight and a reduction of hyperglycaemia after successful pancreatic islet transplantation in STZ-diabetic rats $[12,13]$.

The mechanisms responsible for basement membrane thickening in diabetes are as yet not completely elucidated. Enzymatic glycation of hydroxylysine residues of collagens by glucose and galactose [14], and non-enzymatic glycation of lysine residues by the same sugars at the exposed $\varepsilon-\mathrm{NH}_{2}$ groups have been postulated [15]. Other suggested possibilities include increased synthesis of collagen or other basement membrane proteins such as laminin or fibronectin, either as a primary event or as a compensatory mechanism secondary to decreased production of basement membrane proteoglycan [16]. Increased polyol pathway activity secondary to high ambient glucose levels may play a significant role, since it has been shown that galactosaemia-induced capillary basement membrane thickening can be prevented by aldose reductase inhibitors $[11,17]$. It is, however, not clear as to how an activated polyol pathway may effect the basement membrane.

Thickening of capillary basement membranes in diabetes may be associated with endothelial cell damage $[18,19]$. Repeated endothelial cell death and regeneration with retention of old and the addition of new layers of basement membrane may be a factor in the production of basement membrane duplication and thickening [20]. We failed to demonstrate endothelial cell abnormalities in the present study, whereas we have previously described endothelial cell degeneration in the diabetic BB-rat [21].

Although no report on retinal capillary BMT following pancreatic or islet transplantation is available, the prevention of glomerular basement membrane thickening has been reported following these procedures [22]. Previous studies in the spontaneously diabetic BB-rat and in Sprague-Dawley rats have demon- strated that aging also causes an increase in the BMT $[21,23]$. Since all animals used in this study were agematched, aging as a causative factor of basement membrane thickening in diabetic rats and those with rejected grafts can be eliminated. The remote possibility that streptozotocin per se, might have been responsible for basement membrane thickening in diabetic rats, is eliminated by the fact that successfully transplanted, previously STZ-treated rats did not develop basement membrane thickening. In the current study, increased BMT was seen, both in the superficial and deep vascular beds in animals with hyperglycaemia and was prevented in both capillary beds in animals with successful transplantation. A normally thicker basement membrane in the superficial vascular bed of the retina has been noted in both normal and diabetic rodents $[21,23$, 24]. A gradient in the intravascular pressure over the two capillary systems may be one explanation for these differences [25].

Localised nodular thickening, vacuolation, and deposition of fibrillar material in basement membrane may represent degenerated and entrapped pericyte debris, so-called ghost cells [26]. The finding of projections of basement membrane materials between surrounding glial cells in diabetes have been noted by other investigators [24]. It has been suggested that this redundant basement membrane is laid down as a result of disturbed Müller cell metabolism, which in itself may be a factor responsible for increased BMT in diabetes [29].

The result of this study has demonstrated that successful pancreatic islet cell allotransplantation prevents basement membrane thickening of retinal capillaries in STZ-diabetic rats.

These observations raise hope that successful, pancreatic islet allograft may provide a physiological approach to the management of diabetes and its complications.

Acknowledgements. The present study was supported by grants from the Medical Research Council of Canada and the Canadian National Institute for the Blind.

\section{References}

1. Frank RN (1984) On the pathogenesis of diabetic retinopathy. Ophthalmology 91: 626-634

2. Sutherland DEF, Goetz FC, Ramsay RC, Fryd DS, Najarian JS (1983) Clinical and experimental kidney and pancreas transplantation. In: Little HL, Jack RL, Patz A, Forsham PH (eds) Diabetic retinopathy. Thieme-Straton, New York, pp 199-221

3. Krupin T, Waltman SR, Scharp DW, Oestrich C, Fieldman SD, Becker B, Ballinger WF, Lacy PE (1979) Ocular fluorophotometry in the streptozotocin diabetes mellitus in the rat: effect of pancreatic islet isograft. Invest Ophthalmol Vis Sci 18: $1185-1190$

4. Naeser P, Anderson A (1983) Effect of pancreatic islet implantation on the morphology of retinal capillaries in alloxan diabetic mice. Acta Ophthalmol (Copenh) 61: 38-44 
5. Gray BN, Watkins E Jr (1976) Isolated islet transplantation in experimental diabetes. Aust J Exp Biol Med Sci 54: 57-70

6. Worthen DM, Lee S, Nakaji NT, Sayers HJ, Orloff MJ (1976) Effect of whole pancreas transplantation on eye lesions of alloxan diabetes. Surg Forum 27: 544-546

7. Engerman RL, Meyer RK, Buesseler JA (1964) Effects of alloxan diabetes and steroid hypertension on retinal vasculature. Am J Ophthalmol 58: 965-978

8. Tze WJ, Tai J (1984) Allotransplantation and xenotransplantation of pseudoislets in diabetic rats and mice. Transplantation 38: $438-440$

9. Tze WJ, Tai J (1984) Intracerebral allotransplantation of purified pancreatic endocrine cells and pancreatic islets in diabetic rats. Transplantation 38: 107-111

10. McEwen TAJ, Chakrabarti S, Sima AAF (1987) A rapid reproducible method for determination of basement membrane thickness in biological structures. Comp Biol Med 17: 193-197

11. Robison WG Jr, Kador PF, Kinoshita JH (1983) Retinal capillaries: basement membrane thickening by galactosemia prevented with aldose reductase inhibitor. Science 221: 1177-1179

12. Trimble ER, Karakash C, Malaisse-Lagae F, Vissatine I, Orci L, Renold AE (1980) Effect of intraportal islet transplantation on the transplanted tissue and the recipient pancreas. I. Functional studies. Diabetologia 19: 341-347

13. Nelken D, Friedman EA, Morse SI, Beyer WM (1977) Islet of Langerhans allotransplantation in the rats. Transplant Proc 9: 333-336

14. Spiro RG, Spiro MJ (1971) Studies on the biosynthesis of the hydroxylysine linked disaccharide unit of basement membrane and collagens. III. Tissue and subcellular distribution of glycosyltransferase and the effect of various conditions on the enzyme levels. J Biol Chem 246: 4919-4925

15. Cohen MP, Urdanivia E, Surima M, Wu VY (1980) Increased glycosylation of glomerular basement membrane collagen in diabetes. Biochem Biophys Res Commun 95: 765-769

16. Szarfman A, Hassel JR, Rohrbach DH, Stanley JR, Martin GR (1982) Components of basement membranes: their properties, functions and alteration in the disease state. In: Kuehn $\mathrm{K}$, Schoene HH, Timple R (eds) New trends in basement membrane research. Raven Press, New York, pp 265-275
17. Robison WG Jr, Kador PF, Akagi Y, Kinoshita JH, Gonzalez R, Dvornik D (1986) Prevention of basement membrane thickening in retinal capillaries by a novel inhibitor of aldose reductase, Tolrestat. Diabetes 35: 295-299

18. Ashton $N$ (1974) Vascular basement membrane changes in diabetic retinopathy. Br J Ophthalmol 58: 344-366

19. Williamson JR, Kilo C (1983) Capillary basement membrane in diabetes. Diabetes 32 [Suppl 2]: 96

20. Vracko R, Beneditt EP (1970) Capillary basal lamina thickening. Its relationship to endothelial cell death and replacement. J Cell Biol 47: 281-285

21. Sima AAF, Chakrabarti S, Garcia-Salinas R, Basu PK (1985) the BB-rat - an authentic model of human diabetic retinopathy. Curr Eye Res 4: 1087-1092

22. Mandel TE, Hoffman L, Carter WM (1981) Long term isografts of cultured fetal mouse pancreatic islets. The oncogenic effects of streptozotocin and the prevention of diabetic renal complications. Am J Pathol 104: 227-236

23. Nagata M, Katz ML, Robison GW Jr (1986) Age related thickening of retinal capillary basement membrane. Invest Ophthalmol Vis Sci $27: 437-440$

24. Fischer F, Gartner $\mathbf{J}$ (1983) Morphometric analysis of the basal laminae in rats with long-term streptozotocin diabetes. Exp Eye Res 37: 55-64

25. Williamson JR, Vogler NJ, Kilo C (1971) Microvascular disease in diabetes. Med Clin North Am 55: 847-876

26. Tilton RG, Hoffman PL, Kilo C, Williamson JR (1981) Pericyte degeneration and basement membrane thickening in skeletal muscle capillaries of human diabetes. Diabetes $30: 326-334$

Received: 29 July 1987

and in revised form: 31 December 1987

Dr. A.A. F. Sima

Neuropathology Research Laboratories

University of Manitoba

770 Bannatyne Avenue

Winnipeg, MB, R3E OW3

Canada 